\title{
Inguinal Hernias Repair by Laparascopy. Repair of Inguinal Hernias by Laparascopy
}

\author{
Olga Caridad Leòn Gonzàlez ${ }^{2}$, Pedro Rolando Lòpez Rodrìguez ${ }^{*}$, Luis Manuel Danta Fundora ${ }^{3}$, Jorge Satorre \\ Rocha $^{3}$, Eduardo Garcia Castillo ${ }^{3}$ and Lais Angelica Ceruto Ortiz ${ }^{4}$
}

${ }^{1}$ Specialist I and II Degree in General Surgery, Consultant Professor and Auxiliary Researcher, General Teaching Hospital, Cuba

${ }^{2}$ Specialist I Degree in General Surgery, Auxiliary Professor and Auxiliary Researcher, General Teaching Hospital, Cuba

${ }^{3}$ Specialist I Degree in Genaral Surgery, Auxiliary Professor, General Teaching Hospital, Cuba

${ }^{4}$ Resident of first year in General Surgery, General Teaching Hospital, Cuba

*Corresponding author: Pedro Rolando Lòpez Rodrìguez, Consultant Professor and Auxiliary Researcher, General Teaching Hospital, Havana Cuba

\begin{abstract}
Introduction: A series of 78 laparoscopic hernioplasties performed in the General Teaching Hospital "Enrique Cabrera".

Objective: To determine perioperative events, surgical complications and the evaluation of the pain referred by the operated patients.

Methods: Between January 2012 and December 2018, 78 hernioplasties were performed laparoscopic in 60 patients; 18 had bilateral inguinales hernias. He collected the variables: age, sex, type of hernia, perioperative events and complications, and a pain scale was applied. A database was filled and processed statistically.

Results: The male sex predominated in a 5:1 ratio, the surgical time average was 53.5 minutes for unilateral hernias and 71.3 minutes for the bilateral ones. The most frequent complication in the transoperative period was bleeding lower in $27.0 \%$, and in the postoperative period the hematoma was in $15.3 \%$, it recurred two hernias (2.5\%). At 15 days after surgery, 93.3\% of theoperated did not complain of pain, but the social and labor reintegration was of only $34 \%$ of patients.
\end{abstract} hernias.

Conclusion: laparoscopic inguinal hernioplasty is a therapeutic option more, mainly in patients with bilateral and reproduced

Keywords: Laparoscopic Hernioplasty; Inguinal Hernia; Hernia Recurrence

\section{Introduction}

Since the concept of endoscopic inguinal hernia repair was first described by Ger R [1] in 1982, the endoscopic techniques are gone modifying, going through a time when failures and complications -united to high cost-exceeded initial enthusiasm [2]. Laparoscopic hernioplasty (HL) has been gaining popularity in the last decade, and numerous controlled studies appear in the literature comparing the laparoscopic techniques with conventional techniques [3-7]. In recent years, HL, despite consolidated as a therapeutic option to consider. The advantages of this have been demonstrated method in bilateral hernias, relapsed and in the active labor subject, that requires a precocious labor reintegration [5-7].

\section{Methods}

Between June 2012 and June 2018, a prospective descriptive study of Longitudinal section of 60 patients operated by hernia endoscopy of the region inguinal, in the Department of Surgery of the General Teaching Hospital "Enrique Cabrera". The inclusion criteria were: - Patients who agreed with the type of surgical intervention and the study, and They gave their informed consent. Patients older than 30 years classified ASA I-III, without contraindications anesthetics for laparoscopic interventions.

a) Patients classified as Nyhus III and IV. Exclusion criteria. 
b) Patients with previous surgical wounds in the inguinal region to operate, not dependent on inguinal hernias reproduced.

c) Inguinal hernias complicated, irreducible or slipped.

The surgical techniques were: laparoscopic inguinal hernioplasty completely extraperitoneal (TEP) of total extraperitoneal English and inguinal hernioplasty laparoscopic transabdominal preperitoneum (TAPP) preperitoneal), and one or the other was performed, at the discretion of the main surgeon. The TEP technique was executed with some variants such as: not using the trocar balloon, the preperitoneal space was decoloured by means of the 0 o laparoscope, and the insufflation of $\mathrm{CO} 2$ at $13 \mathrm{mmHg}$. In patients with large herniated rings, placed a polypropylene cone in the hernia defect and then a $15 \times 12 \mathrm{~cm}$ polypropylene prosthesis. There was no need to fix with clips the tights. The TAPP technique was performed on a regular basis [8]. In the immediate postoperative period, the scale of visual pain analog scale was applied (VAS), [9] and a value was assigned to pain through "caritas", which starts very cheerful (value I) until very sad (value X). The quantification of pain was repeated in consultation at 7,15 days and one month after surgery.

\section{Results}

Table 1: Toxicos habits, and personal phalogical history (APP).

\begin{tabular}{|c|c|c|}
\hline Tòxic Habits and APP & Frequency & $\mathbf{\%}$ \\
\hline Chronic Cough & 5 & 8,3 \\
\hline COPD & 3 & 5,0 \\
\hline Constipation & 5 & 8,3 \\
\hline Cardiopathy & 6 & 10,0 \\
\hline Diabetes Mellitus & 6 & 10,0 \\
\hline Tabacco & 24 & 40,0 \\
\hline Excessive Alcohol Consumption & 11 & 18,3 \\
\hline
\end{tabular}

There were operated 78 hernias in 60 patients (18 patients [30.0\%] suffered from bilateral hernias, 69 primary hernias and 9 reproduced hernias). The average of age was 55.6 years, the youngest patient was 30 years and the oldest was 77 years, but the majority (12 patients) were in the fifth decade of life. The male sex predominated in $82.9 \%$, which represented a relationship man / woman of 5: 1. 42.9\% of patients performed large efforts habitual physicists. The pathological history of the patients (Table 1). It is observed that 24 patients $(40.0 \%)$ consumed tobacco, and in 11 an excessive consumption of alcohol was collected 18.3\%. COPD: Chronic Obstructive Pulmonary Disease (Table 2). The distribution of the series according to the Nyhus classification. Right hernias predominated (55.1\%), the indirect variety with large dilation of the ring and destruction of the posterior wall (IIIb) was the most frequent (37 hernias), and 7 femorales hernias and 9 recurrent hernias were operated 73 PET (93.6\%) and 5 TAPP (6.4\%) were performed. Two of the patients in whom a TEP technique was started were converted to a conventional prosthetic technique by accidental perforation of the peritoneum, passing the $\mathrm{CO} 2$ into the peritoneal cavity, and consequently, the loss of the preperitoneal surgical space. Of the 5 TAPP repairs, 3 of them were in the course of a laparoscopic cholecystectomy, and another was the conversion of a failed PET technique. The average surgical time of unilateral hernias was $53.5 \mathrm{~min}$, with a minimum of $25 \mathrm{~min}$ and a maximum of $120 \mathrm{~min}$. In bilateral repairs, the average surgical time was 71.3 min, and a minimum of 40 and a maximum was observed. of 110 minutes.

Table 2: Distribution According to the Nyhus Classification.

\begin{tabular}{|c|c|c|c|c|c|}
\hline \multirow{2}{*}{ Classification } & \multicolumn{2}{|c|}{ Left } & \multicolumn{2}{c|}{ Right } & \multirow{2}{*}{ Total } \\
\cline { 2 - 5 } & Frequency & $\%$ & Frequency & $\%$ & \\
\hline III a & 15 & 35,0 & 10 & 28,5 & $25(32,0 \%)$ \\
\hline III b & 17 & 39,5 & 20 & 57,1 & $37(47,5 \%)$ \\
\hline III c & 5 & 11,6 & 2 & 5,7 & $7(9,0 \%)$ \\
\hline IV & 6 & 14,0 & 3 & 8,5 & $9(11,5 \%)$ \\
\hline Total & 43 & 55,1 & 35 & 44,9 & $78(100 \%)$ \\
\hline
\end{tabular}

The hospital stay was less than $24 \mathrm{~h}$ in 50 patients (71.4\%), in 5 it extended from 24 to $48 \mathrm{~h}$, and in 5 to more than 48 hours. The most frequent complication in the transoperative period (Table 3 ) was minor bleeding in 21 repairs $(27.0 \%)$ that gave rise to 12 hematomas (15.3\%). No complications were observed after the second week, but two patients suffered recurrences (2.5\%), more than two months after surgery. The application and evaluation of the VAS scale (Table 4). In the immediate postoperative period, after the patient recovered from anesthesia, 56 individuals (93.3\%) were classified as VAS I, and 4 as VAS II. Twenty-four hours after surgery, 14 patients (23.3\%) were classified as VAS I, 40 (66.6\%) as VASII, 4 patients as VAS III and 2 VAS IV. In the consultation of the first week of postoperatively, 42 patients $(70.0 \%)$ were classified as VAS I and [10] as VAS II, and two patients with moderate pain (VAS V) appeared in this period. Fifteen days after surgery, 56 individuals (93.3\%) were VAS I and a month were 58 (96.6\%). The incorporation to the usual activities, including work, was 3 patients a week after surgery, at 15 days they were 19 patients (31.6\%) and 54 patients a month $(90.0 \%)$.

Table 3: Complications.

\begin{tabular}{|c|c|c|c|}
\hline Complications & Transoperative & 2 Weeks & After Month \\
\hline Bleeding Miner & $21(27,0 \%)$ & - & - \\
\hline $\begin{array}{c}\text { Accidental } \\
\text { Opening Of the } \\
\text { Peritoneum }\end{array}$ & $8(10,2 \%)$ & - & - \\
\hline Bruising & - & $12(15,3 \%)$ & - \\
\hline Seromas & - & $4(5,1 \%)$ & - \\
\hline Recurrences & - & & $2(2,5 \%)$ \\
\hline
\end{tabular}


Table 4: Evaluation of the Visual Analogy Scale (VAS).

\begin{tabular}{|c|c|c|c|c|c|}
\hline VAS & Immediate preoperative & First Day & First Week & 15 Days & First Month \\
\hline VAS I & $56(93,3 \%)$ & $14(23,3 \%)$ & $42(70,0 \%)$ & $56(93,3 \%)$ & $58(96,6 \%)$ \\
\hline VAS II & $4(6,6 \%)$ & $40(66,6 \%)$ & $10(16,6 \%)$ & $8(13,3 \%)$ & - \\
\hline VAS III & - & $4(6,6 \%)$ & $4(6,6 \%)$ & - & - \\
\hline VAS IV & - & $2(3,3 \%)$ & $2(3,3 \%)$ & - & $4(6,6 \%)$ \\
\hline VAS V & - & - & $2(3,3 \%)$ & - & \\
\hline
\end{tabular}

\section{Discussion}

Currently, with the improvement of laparoscopic techniques, these are outlined as safe, reproducible and as a therapeutic option regardless of the age of the patient; nevertheless, the evaluation of the individual must be correct and meticulous in the preoperative period, specifically cardiorespiratory function, since with the TEP method a working space is created between the sheets of the crosssection sheet, richly vascularized, so that absorption and elimination of $\mathrm{CO} 2$ is greater than that produced in the peritoneal cavity during the performance of the pneumoperitoneum [10]. Although men predominated, there was a slight increase in women in the series with respect to other authors, [3-5] which could have been due to the inclusion in the study of 3 women who underwent the diagnosis of inguinal hernia, in the course of a laparoscopic cholecystectomy. In laparoscopic practice, it is not uncommon finding of hernia defects diagnosed in the transoperative, in men and women, the latter basically with a history of gynecological disorders. Although the usefulness of hernia repairs in asymptomatic patients is questioned in some articles, $[11,12]$ the authors consider that it would be beneficial for the patient, if conditions permit, the repair of the hernia defect by the TAPP method. The relationship between the hernia disease and the physical efforts, is classic from the Cooper era [1]. In the series, $68 \%$ of the patients performed physical activities involving large and medium efforts, and also analyzing the multifactorial character in the pathogenesis of hernia disease, was striking, that approximately half of the patients operated on were smokers, a factor that influences the metabolism of collagen, significantly linked to hernia recurrences [13]. The majority of the repairs were by means of the PET technique, and we consider, as other authors [10,14 -19], that although the TAPP technique brings us closer to the area from a family perspective to the surgeon (peritoneal cavity) and facilitates the so-called "learning curve", the hernial disease - considering it a parietal defect- should be given solution from this same plane to avoid the likelihood of serious complications of intrabdominal, and to leave the transperitoneal method as a tactical resource when the totally extraperitoneal method is unsuccessful.

The average surgical time was similar to other series [3-6]. It is known that this tends to decrease when the surgical team gains experience [16]. The largest surgical time recorded was in a patient, who was started with a PET technique, but Due to technical difficulties, it was converted to a conventional posterior repair. The fundamental complications were in relation to minor bleeding in the transoperative period and postoperative hematomas. In 3 patients it was necessary to drain the hematoma due to the discomfort caused, however, in the rest of the patients with hematomas and seromas they were treated with conservative measures. In two patients, the recurrence occurred 2 months after surgery, which was interpreted as a technical error. Our results coincide with numerous studies [3-7], that indicate the least postoperative pain of the minimum access techniques, as well as a prompt social and labor reincorporation of the patients. Despite the fact that $70 \%$ and $93.3 \%$ a week and 15 days postoperatively, respectively, had no pain or discomfort were minimal, only [18] individuals (30\%) were incorporated into their usual activities before 15 days. These results contrast with other studies that report a return to work and social activities between 10-15 postoperative days, 4-17- although it is likely that some sociocultural factors are influencing these results. It can be concluded by noting that laparoscopic inguinal hernioplasty is another therapeutic option, mainly in patients with bilateral and reproduced hernias. In the series there were no major transoperative or postoperative complications, only minor bleeding and bruising were present. Most patients were not afflicted by pain 2 weeks postoperatively, however, return to social and labor activities after 15 days was low [18-20].

\section{References}

1. Ger R (1982) The management of certain abdominal hernia by intraabdominal closure of the neck of the sac. Ann R Coll Surg Engl 64(5): 342-344.

2. Hernandez Lòpez A (2017) Es la cirugía endoscópica de la hernia inguinal, cirugía avanzada Rev Cirugìa Endoscòpica 17(1): 01-04.

3. David Wright F, Caron Paterson B, Neil Scott B, Alan Hair F, Patrick J (2002) Five-Year Follow-Up of Patients Undergoing Laparoscopic or Open Groin Hernia Repair A Randomized Controlled Trial. Ann Surg 235(3): 333-337.

4. Neumayer L, Giobbie Hurder A, Jonasson O, Fitzgibbons R Jr, Dunlop D, et al. (2004) Open mesh versus laparoscopic mesh repair of inguinal hernia. N Engl J Med 350(18): 1819-1827.

5. Schmedt CG, Leibl R, Bittner BJ (2002) Endoscopic Inguinal Hernia Repair in Comparison with Shouldice and Lichtenstein Repair. Dig Surg 19(6): 511-517.

6. Gokalp A, Inal M, Maralcan G, Baskonus I (2003) A Prospective Randomized Study of Lichtenstein Open Tension-free Versus Laparoscopic Totally Extraperitoneal Techniques for Inguinal Hernia Repair. Acta chir belg 103(5): 502-506.

7. Magnus H, Anders B, Westerdahl J (2008) Laparoscopic extraperitoneal inguinal hernia repair versus open mesh repair: long-term follow-up of a randomized controlled trial. Surgery 143(3): 313-317.

8. Cruz Alonso JR (2010) The endohernioplasty Technical details Arch Cir Gen Dig serial on the Internet.

9. DeLoach LJ, Higgins MS, Caplan AB, Stiff JL (1998) The Visual Analog Scale in the immediate postoperative period: intrasubject variability and correlation with a numeric scale. Anesth 86(1): 102-106. 
10. Olea JM, Diaz Caballero A, Vicens C, Cuadrado A, Valentí V, et al. (2005) Surgery Minimally invasive inguinal hernia. A Sist Sanit Navar 28 (3) 41-50.

11. Gunnarsson U, Degerman M, Davidsson A, Heuman R (1999) Is elective hernia repair worthwhile in old patients? Eur J Surg 165 (4): 326-332.

12. Purkayastha S, Athanasiou T, Tekkis (2005) Inguinal hernia. Clin Evid 13: $327-331$.

13. Bórquez MP, Garrido OL, Manterola DC, Peña P, Schlageter C, et al. (2003) Study of collagen and elastic fibers of the connective tissue of patients with and without primary inguinal hernia. Rev Méd Chile 131(11): 1273-1279.

14. Zamora Amoròs C, Calado Leal C, Illian Riquelme A, Camacho Lozano J, Ripoll Martin R (2012) Cirugìa endoscópica totalmente extraperitoneal extraperitoneal de la hernia inguinal: resultados de 250 hernioplastias. Rev Española Cir 90(8): 501-505.

15. Acuña Barrios J, Elles C, Espiteas B, Martinez E, Carrasquilla R, et al. (2016) Hernioplastias inguinales por via laparascòpica. Experiencia inicial en 324 casos. Rev Hispanoam Hernia 4(3): 87-96.
16. Álvarez Quintero R, Mayagoitia González JC (2005) Hernia surgeon: myth or reality. Cir Gen 27(4): 261-262.

17. Reoyo Pascual JF, Rosa María Martínez Castro, Xandra Valero Cerrato, Raquel León Miranda, Evelio Alonso Alonso, et al. (2015) De la hernioplastia inguinal TAPP a la hernioplastia inguinal TEP: dificultad Peroc Alguna ventaja? Rev Arcircal 2(1): 20-27.

18. Cruz Alonso JR, Abraham Arap J, Lòpez Rodrìguez PR, Leòn Gonzalez OC, Rodrìguez Blanco $\mathrm{H}$, et al. (2012) Laparascòpica repair of inguinal hernias. Rev Cubana Cir 21(2): 183-259.

19. Palmisano EM, Martinez JD, Garcia MM, Gonzalez LG (2018) Key maneuvers and tricks in eTEP. Rev Hispanoam Hernia 6(2): 86-90.

20. Martin Gomez M (2018) Cirugìa Laparascòpica de la hernia inguinal. TEP. Cir Andal 29(2): 174.

\section{(c) (1) \\ This work is licensed under Creative Commons Attribution 4.0 License}

To Submit Your Article Click Here:

Submit Article

DOI: $10.32474 /$ SCSOAJ.2019.03.000156

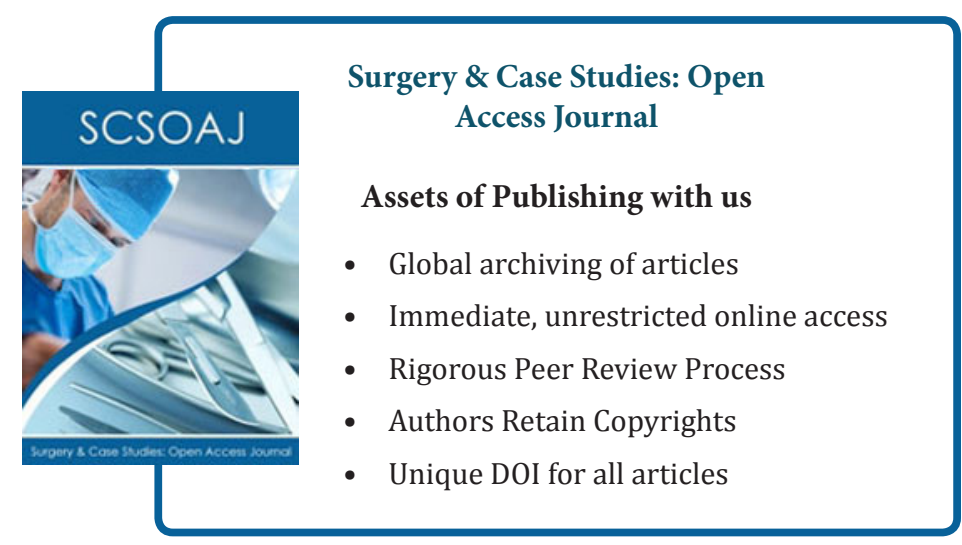

